of the working group were communicated in the hospital's formulary committee meeting, an in-house journal published by the pharmacy and the intranet-based quality management system. The BfArM initiated steps to effect a change of the German SPC at the European level in November 2011.

Conclusions As a result of collaboration between a clinical pharmacist, the medicines information centre, the quality management system and external experts an in-house guideline was developed. At the European level the BfArM intends to bring about a change in the German SPC.

No conflict of interest.

\section{GRP-096 IMPROVING SAFETY OF HIGH RISK MEDICATIONS IN A PSYCHIATRIC HOSPITAL}

doi:10.1136/ejhpharm-2013-000276.096

IJ Costes, 'A Roux-Laplagne, 'B Quillard, 'N Malard-Gasnier, 'L Arnaud, 'L Schadler, ${ }^{2}$ ER Lombertie. ${ }^{1}$ Centre Hospitalier Esquirol, Pharmacy, Limoges, France; ${ }^{2}$ Centre Hospitalier Esquirol, Adult psychiatry, Limoges, France

Background Medicines are major causes of adverse events in hospitalised patients, which can be serious. However, not all drugs carry the same risks.

Purpose The purpose of the study was to identify a list of High Risk Medicines (HRMs) and increase their safety of use in a hospital (25 Care Units (CUs)) where an electronic drug process is in place. Materials and Methods A multidisciplinary team was formed. Its task was to:

- conduct a literature review in order to identify HRMs

- perform an audit to assess drug processes in all CUs

- set up measures to improve the safety of HRMs

Results The literature review led us to establish an HRM list of 14 drugs (including oral/parenteral anticoagulants, anti-arrhythmics, insulins, parenteral hypertonic solutions, adrenergic agonists, opioids and digoxin).

Results of a clinical audit performed in 2011 revealed that $50 \%$ of the 391 referenced oral drug tablets are not fully identifiable until the administration stage; at least one error of storage in medicine cabinet was found in $32 \%$ of CUs; parenteral hypertonic $\mathrm{KCl}$ and $\mathrm{MgSO}_{4}$ solutions were present in $76 \%$ and $28 \%$ of CUs respectively.

Measures taken to improve safety of HRMs were:

- ensure recognition with an alert pictogram for their storage in the pharmacy and CUs

- attribute an electronic HRM alert in prescription software

- re-label blister packs for non-unit packaging HRMs (relevant to $3 / 15$ drugs on the list)

- rationalise keeping hypertonic solutions in CUs

- implement good clinical practise for HRMs and distribute a newsletter about HRM use

- develop a systematic statement of HRM errors

- provide information about relevant HRMs to patients

- arrange training for healthcare professionals

Conclusions Corrective actions should help to improve HRM safety by preventing medication errors. An evaluation of the efficacy of these measures in practise is needed. This work will allow us to meet the requirements of French legislation.

No conflict of interest.

\section{GRP-097 IMPROVING THE QUALITY USE OF MEDICINES IN CHINA BY DEVELOPING THE ROLE OF THE CLINICAL HOSPITAL PHARMACIST: A SYSTEMATIC REVIEW}

doi:10.1136/ejhpharm-2013-000276.097

'Y Li, ${ }^{2} \mathrm{~J}$ Penm, ${ }^{3} \mathrm{SD}$ Zhai, ${ }^{3} \mathrm{YF}$ Hu, ${ }^{2 B}$ Chaar, ${ }^{2} \mathrm{R}$ Moles. 'Peking University, School of Pharmaceutical Sciences, Beijing, China; 'University of Sydney, Faculty of Pharmacy, Sydney, Australia; ${ }^{3}$ Peking University Third Hospital, Department of Pharmacy, Beijing, China
Background China recently initiated ambitious healthcare reforms aiming to provide affordable and equitable basic health care to all by 2020. To meet these goals, new policies issued by China's Ministry of Health surrounding hospital accreditation and antimicrobial use highlighted the role of clinical pharmacy services. International studies highlight the benefits of such services; however to date they have excluded literature reported in Chinese.

Purpose To summarise all available evidence showing the effectiveness of clinical pharmacy services in improving the quality use of medicines in China's hospitals.

Materials and Methods For the English databases, Web of Science, Medline, IPA and Embase were searched using the following keywords: ('pharmacists' OR 'pharmacy' OR 'pharmaceutical services/care') AND ('China'). For the Chinese database, Chinese Biomedical Literature Database on disc was searched using the following keywords: ('clinical pharmacist/pharmacy' OR 'pharmaceutical services/care'). A native bilingual Chinese pharmacist processed relevant Chinese articles.

Results 75 published papers were included. The majority of studies were conducted in the inpatient setting $(68 \%)$, which included clinical pharmacy interventions such as educating doctors and patients, evaluating and monitoring the implementation of hospital policies and reviewing medications on the ward. In the outpatient setting, the majority of studies conducted involved educating patients.

Clinical pharmacy services frequently focused on antimicrobials (44\%). More than half of these studies employed an administrative intervention alongside the clinical pharmacy service. Clinical pharmacy research in China was also found to occur primarily in provincial capital cities (63\%) and to use a comparative study design (61\%). Conclusions Clinical pharmacy services in China, with its unique healthcare system and cultural nuances, appear to positively influence patient care and the appropriate use of medicines. From the published literature, it is expected that clinical pharmacy services could make a strong contribution to China's healthcare reform given further governmental and educational support.

No conflict of interest.

\section{GRP-098 INAPPROPRIATE PRESCRIBING FOR ELDERLY PEOPLE: IS THE HOSPITAL THE INITIATOR?}

doi:10.1136/ejhpharm-2013-000276.098

A Leromain, C Renzullo, J Coutet, JF Penaud. Centre Hospitalier William Morey, Bourgogne, Chalon sur Saône Cedex, France

Background Adverse drug reactions are frequently encountered in older people. They represent the cause of hospitalisation of 10 to $20 \%$ of hospitalised people aged 60 years or over. The quality of geriatric prescription is thus a healthcare priority.

Potentially inappropriate drugs (PIDs) are medicines with an unfavourable benefit/risk ratio or questionable efficacy while other and safer therapeutic alternatives are available.

Purpose To evaluate the quality of prescribing in our hospital for patients who are 75 years old or over. Are PIDs prescribed to our patients? Who first prescribed this treatment: our hospital doctors or family doctors?

Materials and Methods A list of potentially inappropriate medicines, judged by 34 criteria, specially adapted to French medical practise, was used as reference. 28 of these drugs are used in our hospital. We analysed the prescriptions of patients who were 75 years old or over, hospitalised on one day chosen arbitrarily, in order to collect data about their treatments.

Results 133 patients $(29.6 \%$ of patients hospitalised in medical and surgical care units) were included. On average, 8 systemic drugs were prescribed per patient. 31 patients had at least 1 PID prescribed (23.3\%): 24 (18\%) had 1 PID, 5 (3.8\%) had 2 PIDs and 2 (1.6\%) had 